\title{
Inhibition of Listeria monocytogenes ATCC 19115 on ham steak by tea bioactive compounds incorporated into chitosan-coated plastic films
}

\author{
Dan C Vodnar
}

\begin{abstract}
Background: The consumer demands for better quality and safety of food products have given rise to the development and implementation of edible films. The use of antimicrobial films can be a promising tool for controlling $L$. monocytogenes on ready to eat products. The aim of this study was to develop effective antimicrobial films incorporating bioactive compounds from green and black teas into chitosan, for controlling L. monocytogenes ATCC 19115 on vacuum-packaged ham steak. The effectiveness of these antimicrobial films was evaluated at room temperature $\left(20^{\circ} \mathrm{C}\right)$ for 10 days and at refrigerated temperature $\left(4^{\circ} \mathrm{C}\right)$ for 8 weeks.

Results: The HPLC results clearly show that relative concentrations of catechins and caffeine in green tea ranked $E G C G>E G C>C A F>E C G>E C>C$ while in black tea extracts ranked $C A F>E G C G>E C G>E G C>E C>C$. The chitosan-coated plastic films incorporating green tea and black tea extracts shows specific markers identified by FTIR. Incorporating natural extracts into chitosan showed that the growth of $L$ monocytogenes ATCC 19115 was inhibited. The efficacy of antimicrobial effect of tea extracts incorporated into chitosan-coated plastic film was dose dependent. However, chitosan-coated films without addition of tea extracts did not inhibit the growth of L. monocytogenes ATCC 19115. Chitosan-coated plastic films incorporating 4\% Green tea extract was the most effective antimicrobial, reducing the initial counts from 3.2 to $2.65 \mathrm{log} \mathrm{CFU} / \mathrm{cm}^{2}$ during room temperature storage and from 3.2 to $1-1.5 \mathrm{log} \mathrm{CFU} / \mathrm{cm}^{2}$ during refrigerated storage.

Conclusions: Incorporation of tea extracts into the chitosan-coated films considerably enhanced their effectiveness against L. monocytogenes ATCC 19115. 4\% Green tea incorporated into chitosan-coated plastic film had a better antilisterial effect than $2 \%$ green tea or $2 \%$ and $4 \%$ black tea. Data from this study would provide new formulation options for developing antimicrobial packaging films using tea extracts to improve the microbiological safety and quality of ham steak during room and refrigerated storage.
\end{abstract}

\section{Background}

Listeria monocytogenes is a foodborne pathogen in ready to eat products because its ability to survive and grow at refrigeration conditions, its capacity to tolerate relatively high heat and high concentrations of salt [1]. Consuming foods contaminated with $L$. monocytogenes causes the disease listeriosis, which affect especially elderly adults and adults with compromised immune systems and can cause meningitis [2]. The consumer demands for better quality and safety of food products have given rise to the

Correspondence: vodnar_dan@yahoo.co.uk

Food Science and Technology Department, Unit of Chemistry and

Biochemistry, University of Agricultural Sciences and Veterinary Medicine, 3-5 Mănăştur str, Cluj-Napoca 400372, România development and implementation of edible films. The use of antimicrobial films can be a promising tool for controlling L. monocytogenes on ready to eat products [3].

Chitosan, derived by the diacetylation of chitin, is a major component of the shells of crustaceans [4]. Chitosan is a natural polymer, which is non-toxic, biodegradable and biocompatible and has intrinsic antimicrobial activity; however, chitosan film alone had no inhibitory effect on the growth of L. monocytogenes when applied to the surface of ham steaks [1]. Surface application of antimicrobials represents an alternative to direct application and is based on the incorporation of antimicrobial compound into an edible coating that is then applied
(C) Chemistry Central

(C) 2012 Vodnar:; licensee Chemistry Central Ltd. This is an Open Access article distributed under the terms of the Creative Commons Attribution License (http://creativecommons.org/licenses/by/2.0), which permits unrestricted use, distribution, and reproduction in any medium, provided the original work is properly cited. 
onto the food [5]. The choice of active agents that could be incorporated into edible films could influence the consumers perception on ingredients listed on the product label [6]. Thus, a new alternative, by incorporating of natural bioactive compounds into edible films is needed.

After water, tea is one of the most consumed beverages in the world due to the bioactive compounds associated with numerous health benefits $[7,8]$. Studies reports on the benefits of green tea consumption, antioxidant and antimicrobial activity [7]. Obtain from the plant Camellia sinensis, green tea contains higher amounts of bioactive compounds indicating that catechins are the main representatives polyphenols with a wide range of functional and antimicrobial activities [9]. The most important catechins are catechin, epicatechin, epicatechin gallate, epigallocatechin, epigallocatechin gallate [10]. Some studies show that green tea extracts act as inhibiters of food pathogens including Staphylococcus aureus, Shigella disenteriae, Vibrio cholerae, Campylobacter jejuni and Listeria monocytogenes [11]. In black tea, the major polyphenols are tearubigines and theaflavines [12]. The antimicrobial activity of black tea has been also reported [13].

The overall objective of this study was to develop effective antimicrobial films incorporating bioactive compounds from green and black teas, for controlling $L$. monocytogenes ATCC 19115 on vacuum-packaged ham stake. The effectiveness of these antimicrobial films was evaluated at room temperature $\left(20^{\circ} \mathrm{C}\right)$ for 10 days and at refrigerated temperature $\left(4^{\circ} \mathrm{C}\right)$ for 8 weeks.

\section{Results and discussion}

\section{HPLC characterization of tea extracts}

HPLC analysis of catechins and caffeine contained in green and black teas was performed. Based on the retention times of the peaks from the chromatograms (Figure 1), each peaks of 2 samples, tea extracts and authentic standards, were compared. The concentration of catechins and caffeine in the green tea and black tea extracts are presented in Table 1 . There was a variation in the concentration of catechins between the green and black tea extracts analyzed. The green tea extract showed higher amounts in all investigated catechins and caffeine then black tea extract. Considerable variation in the levels of catechins has been reported in several studies $[14,15]$. Comparing the levels of catechins presented in Table 1, relative concentrations of catechins and caffeine in green tea ranked EGCG $>\mathrm{EGC}>\mathrm{CAF}>\mathrm{ECG}>\mathrm{EC}>$ $\mathrm{C}$ while in black tea extracts ranked CAF $>$ EGCG $>$ $\mathrm{ECG}>\mathrm{EGC}>\mathrm{EC}>\mathrm{C}$. Some studies found the following relative concentration of catechins: EGCG $>$ ECG $>$ EC $>C$ [15]. The results found for the green tea extracts followed this same sequence reported also by Saito et al. [16]. With regard to caffeine, the black tea extract had a

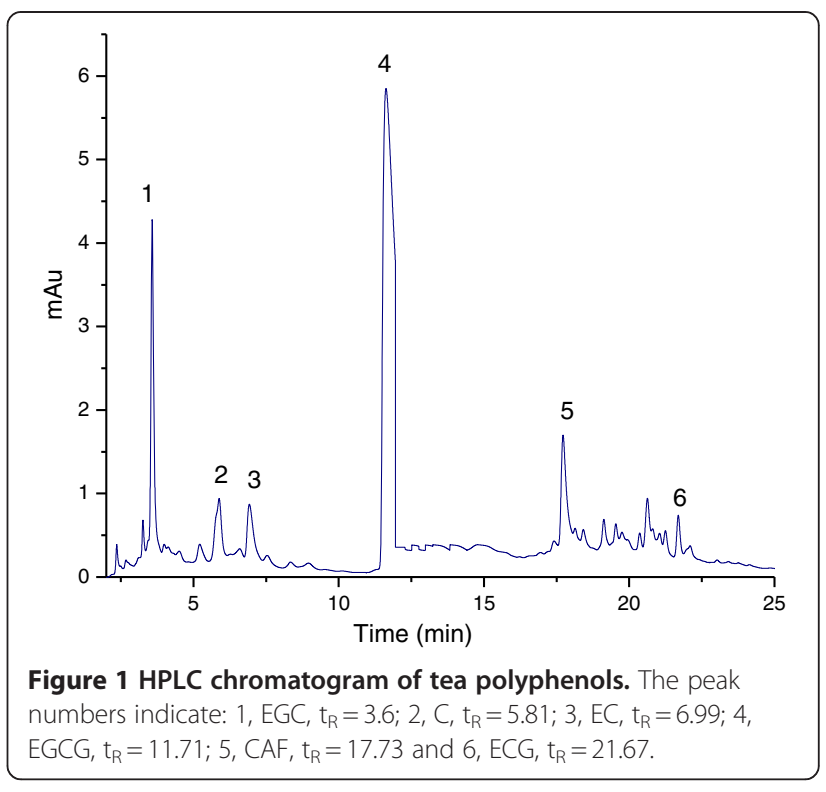

higher concentration than green tea as showed in table 1. In addition, it can be noted that the level of catechins and caffeine in green tea and black tea extracts increased once with their concentrations.

\section{FTIR spectroscopy}

FTIR spectroscopy is expected to be especially valuable in analyzing the phase structure and the interaction between chitosan and green tea extracts. The infrared spectra of chitosan films with and without addition of $2 \%$ or $4 \%$ green tea extracts and their blends are shown in Figure 2. Stretching vibration of hydroxyl groups $(-\mathrm{OH})$ appeared around $3327 \mathrm{~cm}^{-1}$ in all samples and indicated intermolecular bonding of chitosan molecules. The peak at $2897 \mathrm{~cm}^{-1}$, corresponded to $\mathrm{C}-\mathrm{H}$ stretching, while the band at $1336 \mathrm{~cm}^{-1}$ was the $\mathrm{O}-\mathrm{H}$ of water. The chitosan film spectrum was very similar to that reported by Bourtoom et al. [17]. The region between 1631$1735 \mathrm{~cm}^{-1}$ corresponded to $\mathrm{C}=\mathrm{O}$ stretching (amide I) and the peak at $895 \mathrm{~cm}^{-1}$ suggested the presence of an ether group in the film. The chemical interactions are reflected by changes in peaks of characteristics spectra after blending the chitosan with tea extracts. The

Table 1 Main concentration ( $\mathrm{mg} \%$ ) of catechins and caffeine in green (GT) and black teas (BT) extracts

\begin{tabular}{ccrrrr}
\hline Signal & Compound & \multicolumn{1}{c}{$\mathbf{2 \%}$ GT } & \multicolumn{1}{c}{$\mathbf{4 \%}$ GT } & \multicolumn{1}{c}{$\% \mathbf{B T}$} & $\mathbf{4 \% ~ B T}$ \\
\hline 1. & EGC & $204.2 \pm 4.2$ & $408.5 \pm 8.9$ & $18.9 \pm 0.4$ & $36.6 \pm 0.3$ \\
2. & C & $9.4 \pm 0.4$ & $18.6 \pm 5.2$ & $7.5 \pm 0.1$ & $15.0 \pm 0.2$ \\
3. & EC & $13.1 \pm 0.1$ & $26.4 \pm 0.5$ & $10 \pm 0.1$ & $20 \pm 0.3$ \\
4. & EGCG & $240.8 \pm 3.6$ & $481.6 \pm 6.2$ & $54.0 \pm 1$ & $109.8 \pm 1.4$ \\
5. & CAF & $103.6 \pm 1.8$ & $207.4 \pm 3.7$ & $89.6 \pm 0.8$ & $178.5 \pm 2.1$ \\
6. & ECG & $67.8 \pm 1.4$ & $131.4 \pm 1.6$ & $43.6 \pm 0.8$ & $86.5 \pm 1.6$ \\
\hline
\end{tabular}




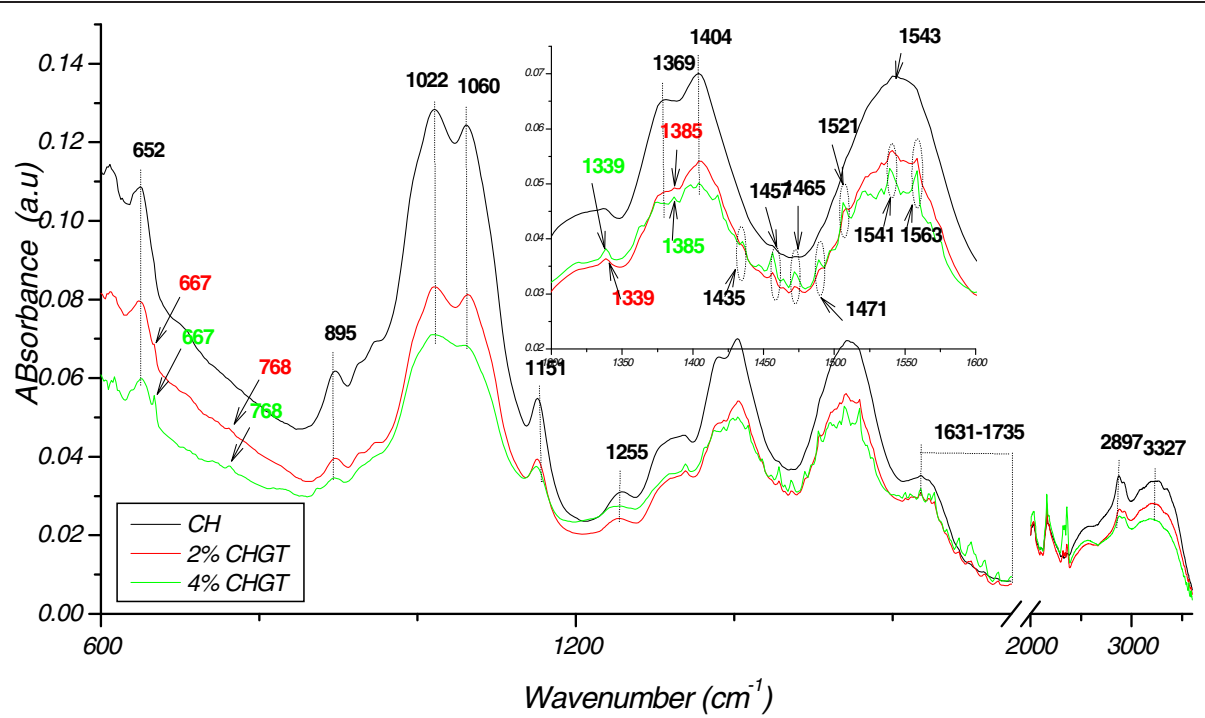

Figure 2 FTIR spectra of chitosan film (CH), Chitosan incorporating 2\% (CHGT2\%) and 4\% (CHGT4\%) green tea extract.

characteristic peaks for green tea and black tea (not shown) appeared as a small shoulder at 667,768 , and in the region between $1339-1563 \mathrm{~cm}^{-1}$ specify for $\mathrm{C}=\mathrm{O}$ NHR, amine, $-\mathrm{NH}_{2}$, and ammonium. Spectra showed a peck near $1400 \mathrm{~cm}^{-1}$, which was the same pattern as reported by Vodnar et al. [18].

\section{Effect of active films on the growth of $L$. monocytogenes} ATCC 19115 on ham steaks at room temperature storage The antimicrobial activity of chitosan has been showed in many studies $[19,20]$ but antimicrobial proprieties may become negligible when it is use in the form of insoluble films [21]. Several studies showed the antimicrobial effect of commercial substances such as nisin, sodium lactate $[21,22]$, but have disadvantages, nisin is relatively expensive and the utilization in high levels would be prohibited for the food industry, sodium lactate needs to be incorporated into high concentration to have antimicrobial properties. Additionally, the utilization of high levels of antimicrobials can have a negative impact on the customer perceptions.

The effect of tea extracts incorporated into chitosancoated plastic films on the growth of L. monocytogenes ATCC 19115 on ham steaks is shown in Figure 3. The initial concentration of $L$. monocytogenes ATCC 19115 on inoculated ham steak samples was $3.2 \log \mathrm{CFU} / \mathrm{cm}^{2}$. L. monocytogenes ATCC 19115 in chitosan-coated plastic films grew to $6.8 \log \mathrm{CFU} / \mathrm{cm}^{2}$ after 10 days of storage at room temperature. In control ham steak sample, the count reached $6.9 \log \mathrm{CFU} / \mathrm{cm}^{2}$ after 10 days, demonstrating the ability for the pathogen to grow rapidly in package without tea extracts. Incorporating natural extracts into chitosan showed that the growth of $L$. monocytogenes ATCC 19115 was inhibited. 4\% CHGT was the most effective antimicrobial reducing the initial counts from 3.2 to $2.65 \mathrm{log} \mathrm{CFU} / \mathrm{cm}^{2}$ after 10 days of room storage. The counts of $L$. monocytogenes ATCC 19115 in samples $2 \%$ CHGT, 2\% CHBT, 4\% CHBT were not statistically significant $(\mathrm{p}<0.05)$. In all samples the growth of L. monocytogenes ATCC 19115 is progressive from 1 to 10 days, exception sample 4\% CHBT where is registered a constant inhibition of pathogen. The efficacy of antimicrobial effect of tea extracts incorporated into chitosan-coated plastic film was dose dependent. The $2 \%$ green tea and $2 \%, 4 \%$ black tea extracts had inhibitory effect on $L$.monocytogenes ATCC 19115 but the most efficient antimicrobial effect has been registered by

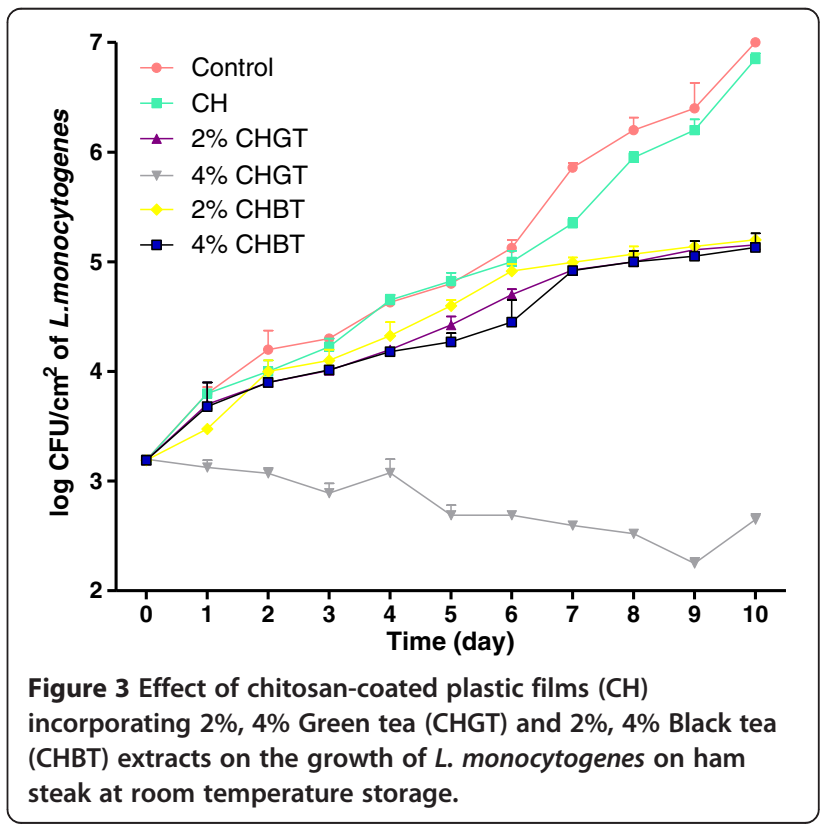


4\% CHGT. The chitosan-coated plastic film $(\mathrm{CH})$ and the control samples showed a very similar growth rate of L. monocytogenes ATCC 19115. A possible explanation is that chitosan is ineffective in films because has a low rate of diffusion in a compact matrix like ham steak [21]. Compare with chitosan the incorporated tea extracts had varying efficacy but all of them are able to migrate from the chitosan film to ham steak. The concentration of tea extracts, the interaction with food components and the diffusion rate of them could signify the antimicrobial activity of biofilms.

\section{Effect of active films on the growth of $L$. monocytogenes} ATCC 19115 on ham steaks during refrigerated storage Inoculated ham steak samples with an initial population of $3.2 \log \mathrm{CFU} / \mathrm{cm}^{2}$, were stored at $4{ }^{\circ} \mathrm{C}$ for 8 weeks. Counts of L. monocytogenes ATCC 19115 on ham steak samples treated with chitosan-coated film incorporating tea extracts are shown in Figure 4. In the first 3 weeks, L. monocytogenes ATCC 19115 in control and chitosancoated plastic film grew very slowly from 3.2 to $4.1 \mathrm{log}$ $\mathrm{CFU} / \mathrm{cm}^{2}$. It started to growth rapidly for week 3 and reached $6.3 \log \mathrm{CFU} / \mathrm{cm}^{2}$ for control sample and 5.5log $\mathrm{CFU} / \mathrm{cm}^{2}$ for $\mathrm{CH}$ sample after 8 weeks storage at $4^{\circ} \mathrm{C}$. The tea extracts addition into chitosan-coated films were effective against $L$ monocytogenes ATCC 19115 and reduced its counts from 3.2 to $1-1.5 \log \mathrm{CFU} / \mathrm{cm}^{2}$ during 8 weeks of storage. The treatment with $4 \%$ CHGT was the most effective and completely inhibited the growth of L. monocytogenes ATCC 19115 after 8 weeks storage of $4^{\circ} \mathrm{C}$, decreasing from 3.2 to $1 \log \mathrm{CFU} / \mathrm{cm}^{2}$. These results demonstrate that chitosan-coated plastic films incorporated with $4 \%$ CHGT could be use to

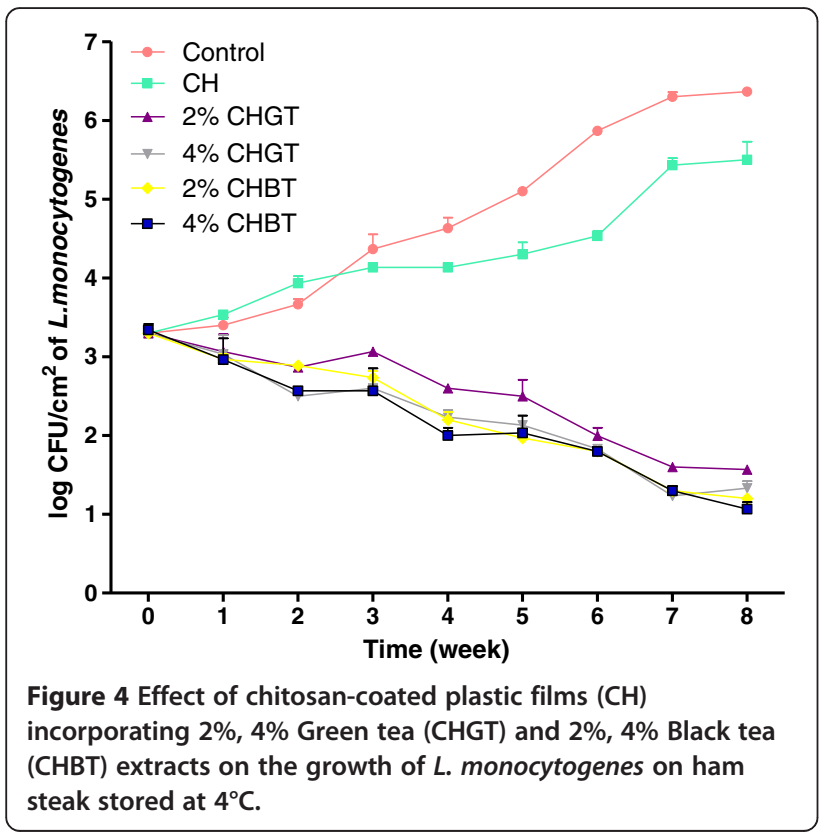

control L. monocytogenes ATCC 19115 on ham steaks. Several studies have shown that the polyphenolic components in green and black teas effectively inhibit the growth of S. mutans and S. sobrinus [23,24]. Almajano et al. [25] found that the strain B. cereus is a very sensitive bacterium showing the largest inhibition rate in the presence of tea extracts. In general the gram negative bacteria are more resistant to polyphenols than Gram positive bacteria, perhaps due to the different cell wall compositions [26].

Others have studied the decline of $L$. monocytogenes on low-moisture ready-to eat meat products. $L$ monocytogenes declined on vacuum-packaged beef snack sticks by $1 \log$ CFU/sample in 5 days [27]. In inoculated pepperoni and vacuum-packed $L$. monocytogenes decreased $>1.5>2.5$ and $>3 \log \mathrm{CFU} / \mathrm{cm}^{2}$ on samples stored at 4,12 , or $25^{\circ} \mathrm{C}$, respectively [28]. Chitosan is a polymer that imparts minimal adverse sensory properties to food [1]. The quality properties of pork sausage prepared with water-soluble chitosan has been investigated and no differences in colour flavour, texture, overall acceptance and mechanical texture was detected by Jo et al. [29]. As such, this study assume that green tea and black tea extracts and chitosan at the levels described, would not affect the organoleptic properties of ham steaks and the results cannot be extrapolated to the species as a whole without further work.

The antilisterial activity was higher in chitosan-coated plastic film incorporating $4 \%$ green tea. These results demonstrated that the antimicrobial films developed in this study could potentially be used to extend the microbial shelf life of ham steak.

\section{Conclusions}

The results of this study clearly show that relative concentrations of catechins and caffeine in green tea ranked EGCG $>$ EGC $>$ CAF $>$ ECG $>$ EC $>C$ while in black tea extracts ranked $\mathrm{CAF}>\mathrm{EGCG}>\mathrm{ECG}>\mathrm{EGC}>\mathrm{EC}>\mathrm{C}$. The FTIR spectra indicated that interactions and molecular miscibility were present between the major components of green tea, black tea extracts and chitosan.

The effect of chitosan-coated plastic film incorporating green tea and black tea extracts on the growth of $L$. monocytogenes ATCC 19115 in ham steak was investigated during room and refrigerated storage. However, chitosan-coated films without addition of tea extracts did not inhibit the growth of $L$. monocytogenes ATCC 19115. Incorporation of tea extracts into the chitosancoated plastic films considerably enhanced their effectiveness against L. monocytogenes ATCC 19115. 4\% Green tea incorporating into chitosan-coated film had a better antilisterial effect than $2 \%$ green tea, $2 \%, 4 \%$ black tea. 
Data from this study would provide new formulation options for developing antimicrobial packaging films using tea extracts to improve the microbiological safety and quality of ham steak during room and refrigerated storage.

\section{Methods}

\section{Preparation of tea extracts}

Green tea (GT) and Black tea (BT) were purchased from a Romanian market. The aqueous extracts were made by adding $100 \mathrm{ml}$ water $\left(100^{\circ} \mathrm{C}\right)$ to $1 \mathrm{~g}$ or $2 \mathrm{~g}$ tealeaves and brewing for $10 \mathrm{~min}$ with stirring and removing solid matter by filtration.

\section{Chemical characterization of tea extracts}

A HPLC Agilent Technologies 1200 Series chromatograph coupled with UV-VIS detector and an HPLC column Supelcosil LC-18 column (Sigma-Aldrich Co), $5 \mu \mathrm{m}, 25 \mathrm{~cm} \times 4.6 \mathrm{~mm}$ was used. The gradient elution was performed with mobile phase A, composed of methanol: acetic acid: double distilled water (10:2:88 v/v/ v) and mobile phase B, comprising methanol: acetic acid: double distilled water $(90: 3: 7 \mathrm{v} / \mathrm{v} / \mathrm{v})$, at a flow rate of $1.0 \mathrm{ml} / \mathrm{min}$. All solvents were HPLC grade solvents, filtered through a $0.45-\mu \mathrm{M}$ membrane (Millipore, U.S.A.) and degassed in an ultrasonic bath before use. The chromatograms were monitored at $280 \mathrm{~nm}$.

\section{Culture growth conditions}

L. monocytogenes ATCC 19115 was maintained on Oxford agar (Sifin, Germany) agar plates at $4^{\circ} \mathrm{C}$. For growth, a single colony of $L$. monocytogenes was inoculated into a tube of tryptic soy broth plus $0.7 \%$ yeast extract (TSBYE) (Difco Laboratories) and incubated at $35^{\circ} \mathrm{C}$ for $24 \mathrm{~h}$. The culture was then transferred to $10 \mathrm{ml}$ of fresh and incubated for $24 \mathrm{~h}$ at $35^{\circ} \mathrm{C}$ for $24 \mathrm{~h}$ to reach a final concentration of $10^{9} \mathrm{CFU} / \mathrm{ml}$.

\section{Preparation of antimicrobial films}

Two grams of low molecular weight (LMW) chitosan (Sigma Aldrich, Germany) were dissolved in $100 \mathrm{ml}$ of $1 \%(\mathrm{w} / \mathrm{v})$ acetic acid and stirred overnight at room temperature. Hydroxypropyl methylcellulose (HPMC) (Sigma-Aldrich) solution was prepared by dissolving $3 \mathrm{~g}$ of HPMC in $100 \mathrm{ml}$ of $1 \%$ acetic acid. The coating solution was prepared by mixing 12 parts of chitosan solution with 2 parts of HPMC solution and 1 part of tea extract. A Surlyn ${ }^{\circledR}$ film (1-mil) was taped into $20 \times 20 \mathrm{~cm}$ glass plates and $15 \mathrm{ml}$ of chitosan solution was cast onto the plastic film using a thin-layer chromatography plate coater (TLC, Switzerland). The gate of the TLC coater was fixed at $500 \mu \mathrm{m}$ to control the thickness of the coating. The chitosan-coated film incorporating 1\%, $2 \%$ green tea and black tea extracts. The coated films were air-dried at room temperature overnight.

\section{FTIR characterization of antimictobial films}

FTIR spectra using attenuated total reflectance (ATR) and an internal reflection accessory made of composite zinc selenide $(\mathrm{ZnSe})$ and diamond crystals were obtained on a Schimatzu IR Prestige- 21 spectrometer. Each spectrum was registered from 4000 to $500 \mathrm{~cm}^{-1}$. The FTIR spectra were recorded for all samples in parallel with controls. Three spectra were acquired for each trial variant at room temperature. Each spectrum was composed of an average of 128 separate scans. The measuring time was approximately 9 minutes per sample $(n=3)$, depending on the number of scans per spectrum. Accordingly, as the average number of scans increased, the measuring time increased.

\section{Inoculation of ham steak}

Freshly processed ham steak samples were obtained from a local retailer. They were kept frozen at $-20^{\circ} \mathrm{C}$ and thawed at $2^{\circ} \mathrm{C}$ for 1 day immediately before use as described by Besse et al. [30]. Slices of ham steak were punched aseptically into $6.2 \mathrm{~cm}$ diameter round pieces weighing $26.4 \mathrm{~g}$ with a surface area of $25.9 \mathrm{~cm}^{2}$ on one side. The ham steak discs were placed onto a piece of sterile aluminium foil, $125 \mu \mathrm{l}$ of $L$. monocytogenes ATCC 19115 was spread on one side of the ham steak surfaces, and the sample were left undisturbed for $5 \mathrm{~min}$ to allow the inoculum to soak in and the cells to attach. The ham steak discs were then flipped and the same procedure was repeated for the other side of each sample thus achieving the final concentration of $2 \times 10^{3} \mathrm{CFU} / \mathrm{cm}^{2}$ of ham steak surface. After inoculation, ham steak discs were kept at $4^{\circ} \mathrm{C}$ for 20 minutes to allow bacterial attachment.

\section{Packaging of inoculated ham steak samples with antimicrobial films}

The inoculated samples were wrapped in the antimicrobial and control films prepared as described above. The wrapped samples were then inserted into 3-mm thick high barrier pouches (nylon/polyethylene, Koch Supplies) and subsequently sealed using vacuum-packaging machine (Bag Unit, Zepter). The packages were stored at $20^{\circ} \mathrm{C}$ for 10 days. Instead of using $4^{\circ} \mathrm{C}$, a typical refrigerated storage temperature for this kind of products, a relative high temperature was used to accelerate the selection of the most effective antimicrobial concentration of green and black tea against L. monocytogenes ATCC 19115. The packages prepared for refrigeration storage $\left(4^{\circ} \mathrm{C}, 8\right.$ weeks) were analyzed weekly. 


\section{Analysis of $L$. monocytogenes in the samples}

The samples were analyzed for $L$. monocytogenes ATCC 19115 every 2 days over the storage period. For determination of L. monocytogenes ATCC 19115 counts, a package was opened aseptically and contents were transferred to a sterile stomacher bag and homogenized for 2 min with $100 \mathrm{ml}$ of $0.9 \% \mathrm{NaCl}$ water. Counts of $L$. monocytogenes ATCC 19115 were determined by an overlay method [31]. The plates were incubated at $35^{\circ} \mathrm{C}$ for $48 \mathrm{~h}$ and black colonies were counted.

\section{Statistical analysis}

Results for 3 individual experiments were used to calculate the mean of cell counts. Analysis of variance (ANOVA) and Duncan's multiple range tests were performed to analyze the results. Significance of difference was defined at the $5 \%$ level $(\mathrm{P}<0.05)$. All statistical analysis was carried out using Graph Pad Version 4.0 (Graph Pad Software Inc; San Diego, CA, USA).

\section{Abbreviations}

BT: Black tea; C: Catechin; CAF: Caffeine; CH: Chitosan-Coated plastic film; CHBT: Chitosan-coated plastic film incorporating Black Tea extract; CHGT: Chitosan-coated plastic film incorporating Green Tea extract; EC: Epicatechin; ECG: Epicatechin Gallate; EGC: Epigallocatechin; EGCG: Epigallocatechin Gallate; GT: Green Tea.

\section{Competing interests}

The author declares no competing interests.

\section{Authors' contributions}

DCV carried out all experiments and prepared the final manuscript.

\section{Acknowledgements}

This work has supported by a research grant of University of Agricultural Sciences and Veterinary Medicine, Cluj-Napoca.

Received: 24 June 2012 Accepted: 19 July 2012

Published: 28 July 2012

\section{References}

1. Ye M, Neetoo H, Chen $\mathrm{H}$ : Control of Listeria monocytogenes on ham steaks by antimicrobials incorporated into chitosan- coated plastic films. Food Microb 2008, 25:260-268.

2. Roberts D, Greenwood M: Listeria monocytogenes. Massachusetts: Practical Food Microbiology; 2003

3. Lungu B, Johnson MG: Fate of Listeria monocytogenes inoculated onto the surface of model turkey frankfurter pieces treated with zein coatings containing nisin, sodium diacetate, and sodium lactate at $4^{\circ} \mathrm{C}$. J Food Prot 2005, 68:855-859.

4. No HK, Park NY, Lee SH, Samuel PM: Antibacterial activity of chitosan and chitosan oligomers with different molecular weights. Int J Food Microbiol 2002, 74:65-72.

5. Cagri A, Ustunol Z, Ryser ET: Antimicrobial edible films and coatings. J Food Prot 2004, 67:833-848

6. Jiang $Z$, Neetoo $H$, Chen H: Efficacy of freezing, frozen storage and edible antimicrobial coatings used in combination for control of Listeria monocytogenes on roasted turkey stored at chiller temperatures. Food Microb 2011, 28:1394-1401.

7. Khan N, Mukhtar H: Tea polyphenols for health promotion. Life Sci 2007, 81:519-533.

8. Dulf FV, Andrei S, Bunea A, Socaciu C: Fatty acid and phytosterol contents of some Romanian wild and cultivated berry pomaces. Chem Pap 2012 66(925):93.
9. Pastore RL, Fratellone P: Potential health benefits of green tea (Camellia sinesnis): A Narrative Review. Explore 2006, 2:531-539.

10. Vodnar DC, Socaciu C: Green tea increases the survival yield of Bifidobacteria in simulated gastrointestinal environment and during refrigerated conditions. Chem Central J 2012, 6:61.

11. Taguri T, Tanaka T, Kouno I: Antimicrobial activity of 10 different plant polyphenols against bacteria causing food-borne disease. Biol Pharm Bull 2004, 27:1965-1969.

12. Graham HN: Tea. New Jersey: John Wiley and Sons; 1999.

13. Bancirova M: Comparison of the antioxidant capacity and the antimicrobial activity of black and green tea. Food Res Int 2010, 43:1379-1382.

14. Khokhar S, Magnusdottir MGS: Total phenol, catechin, and caffeine contents of teas commoonly consumed in the United Kingdom. J Agr Food Chem 2002, 50:565-570

15. Mizukam Y Sawai Y Yamaguchi Y. Simultaneous analysis of catechins, gallic acid, strictinin, and purine alkaloids in green tea by using catecol as an internal standard. J Agr Food Chem 2007, 55:4957-4964.

16. Saito TS, Welzel A, Suyenaga ES, Bueno F: A method for fast determination of epigallocatechin gallate (EGCG), epicatechin (EC), catechin (C) and caffeine (CAF) in green tea using HPLC. Cien Tec Ali 2006, 26:394-400.

17. Bourtoom T, Chinnan MS: Preparation and properties of rice starchchitosan blend biodegradable film. LWT- Food Sci Technol 2008, 41:1633-1641

18. Vodnar DC, Pop OL, Socaciu C: Monitoring lactic acid fermentation in media containing dandelion (Taraxacum officinale) by FTIR Spectroscopy. Not Bot Horti Agrobo 2012, 40:65-68.

19. Sudarshan NR, Hoover DG, Knorr D: Antibacterial action of chitosan. Food Biotechnol 1992, 6:257-272.

20. Wang GH: Inhibition and inactivation of five species of foodborne pathogens by chitosan. J Food Prot 1992, 55:916-919.

21. Ye M, Neetoo H, Chen H: Effectiveness of chitosan coated plastic films incorporating antimicrobials in inhibition of L. monocytogenes on coldsmoked salmon. Int J Food Microb 2008, 127.235-240.

22. Mbandi $E$, Shelef $L A$ : Enhanced antimicrobial effects of combination of lactate and diacetate on Listeria monocytogenes and Salmonella spp. in beef bologna. Int J Food Microb 2008, 76:191-198.

23. Otake S, Makimura M, Kuroki T, Nishihara Y, Hirasawa M: Anticaries effects of phenolic compounds from Japanese green tea. Caries Res 1991, 25:438-443.

24. Sasaki H, Matsumoto M, Tanaka T, Maeda M, Nakai M, Hamada S, Oshima T: Antibacterial activity of polyphenol compounds in oolong tea extract against Streptococcus mutans. Caries Res 2003, 38:2-8.

25. Almajano MP, Carbo R, Lopez Jimenez JA, Gordon MH: Antioxidant and antimicrobial activities of tea infusions. Food Chem 2008, 108:55-63.

26. Negi PS, Jayaprakasha GK, Jena BS: Antioxidant and antimutagenic activities of pomegranate peel extracts. Food Chem 2003, 80:393-397.

27. Ingham SC, Buege DR, Dropp BK, Losinski JA: Survival of Listeria monocytogenes during storage of ready-to-eat products processed by drying, fermentation, and/or smoking. J Food Prot 2004, 67:2698-2702.

28. Byelashov OA, Carlson BA, Geornaras I, Kendall PA, Scanga JA, Sofos JN: Fate of post-processing inoculated Listeria monocytogenes on vacuumpackaged pepperoni stored at 4,12 or $25^{\circ} \mathrm{C}$. Food Microbiol 2009, 26:77-81.

29. Jo C, Lee JW, Lee KH, Byun MW: Quality properties of pork sausage prepared with water-soluble chitosan oligomer. Meat Sci 2001, 59:369-375

30. Besse NG, Audinet N, Beaufort A, Colin P, Cornu M, Lombard B: A contribution to the improvement of Listeria monocytogenes enumeration in cold smoked salmon. Int J Food Microb 2004, 91:119-127.

31. Kang DH, Fung DYC: Thin agar layer method for recovery of heat-injured Listeria monocytogenes. J Food Prot 1999, 62:1346-1349.

doi:10.1186/1752-153X-6-74

Cite this article as: Vodnar: Inhibition of Listeria monocytogenes ATCC 19115 on ham steak by tea bioactive compounds incorporated into chitosan-coated plastic films. Chemistry Central Journal 2012 6:74. 